\title{
Escrituras escénicas y prácticas colaborativas como devenir político del acontecimiento teatral
}

\author{
Scenic Scriptures and Collaborative Practices as a Political Procedure of the Theater \\ Development
}

Verónica Manzone ${ }^{a}$

\begin{abstract}
:
The present essay has as purpose reflect about group notions, collaborative practice and the tensions between body, text and scene from the analysis of the creative process of the theatre play Inventario de un jardín que arde (2017). The study aims to deepen the notion of stage Dramaturgy, to observe changes in the term dramaturgy in response to the need to open and revise certain theatrical and literary categories.
\end{abstract}

Keywords:

collaborative practices, dramaturgies, body, text, group

\section{Resumen:}

El presente ensayo tiene como objetivo reflexionar acerca de las nociones de grupo, prácticas colaborativas y las potentes tensiones entre cuerpo, texto y escena a partir del análisis del proceso creativo de la obra Inventario de un jardín que arde (2017). El estudio pretende profundizar la noción dramaturgia escénica, observar modificaciones en torno al término dramaturgia como respuesta a la necesidad de apertura y revisión de ciertas categorías teatrales y literarias.

Palabras Clave:

prácticas colaborativas, dramaturgias, cuerpo, texto, grupo

\section{INTRODUCCIÓN}

“(...) el arte no es político por su temática sino por su modo o procedimiento formal de acción. Deviene político cuando propone una interrupción en las reglas de la cultura y de la ley. Deviene político cuando se transforma en potencia para cuestionar y desestabilizar al espectador en la construcción de su identidad y realidad, extendiéndose más allá del mimético y aristotélico sistema de representación y reproducción de ideologías existentes y prevalecientes" (García, 2012)

Si partimos de la idea de que todo acto es político, en el teatro esto toma una dimensión aun mayor, puesto que nuestros actos pasan de la intimidad del ensayo al carácter público del acontecimiento escénico, aun siendo arte minoritario el teatro produce asamblea, funda su existencia en la reunión de cuerpos, no hay teatro sin convivio ${ }^{1}$ (Dubatti, 2003).

La primera instancia de reunión, se presenta en el ensayo, en la constitución de grupos. El teatro así por su carácter colectivo crea en sí mismo su propio sistema de devenir micropolítico. La forma en la que se vinculan los participantes, la elección del material, el modo de producción, su relación con el campo teatral, entre otras cosas, instalan al colectivo ante la toma de decisiones políticas. ¿Se puede separar lo ético de lo estético? ¿Desde dónde y cómo construir escena? En nuestro caso en particular, estas preguntas se hicieron parte fundante de los procedimientos escénicos y de la creación en sí misma. Nuestro trabajo teatral está atravesado por interrogantes en torno al teatro y, más claramente, a la tradición heredada de la institución Teatro y sus mandatos.

\footnotetext{
${ }^{1}$ Para ahondar en la teoría del convivio recomendamos leer el libro de Jorge Dubatti donde expone con precisión sus lineamientos El convivio teatral. teoría y práctica del teatro comparado. (2003)
}

${ }^{a}$ Es Profesora Titular de la Cátedra de Historia de la cultura y el teatro argentinos II, Facultad de Artes Diseño (UNCuyo), actriz y directora teatral. Contacto: mv.manzone@gmail.com 
Inventario de un jardín que arde (2017), obra que deseamos analizar, nace como necesidad de creación propia que nos permitiera el encuentro de un lenguaje singular y genuino. El primer cruce con dichos mandatos fue la decisión de crear un grupo conformado enteramente por mujeres (directoras, actrices, escenógrafas, técnicas, etc.). El segundo desafío fue con el destierro del mandato de padre- texto, su destronamiento como el rector escénico (su teatralidad pre-cocida), debido a ello trabajamos sin texto a priori, buscando constantemente la creación teatral vinculada a una dramaturgia de la escena, colocando en un mismo nivel jerárquico a todos los materiales textuales y no textuales, teatrales y no teatrales. Lo que nos lleva al tercer y cuarto cruce como profundizaciones del anterior: la unicidad con la que siempre se ha canonizado el rol de la autoría y de la dirección teatral, por lo cual para ahondar nuestra premisa política decidimos adentrarnos al juego de las prácticas colaborativas apostando por una dramaturgia de autoría compleja y en la duplicación del rol de la dirección.

Encarar un proceso ligado a la provocación, consciente o inconsciente, de estas tradiciones heredadas de la institución Teatro, funcionó en un primer momento como motor de la pulsión creadora. El deseo creativo no pasaba por una temática escogida y unificadora, un texto a priori, o una técnica en particular, sino la sensación de estar cometiendo parricidio en todos los sentidos (metodológica, procedimental y estéticamente), esta pulsión instalaba nuestra praxis sobre constantes cuestionamientos sobre nuestro modo de ver el arte, en general, y en particular el modo de habitar la escena. ¿Qué significaba encarnar un texto? ¿Dónde quedaba nuestro cuerpo en esa ecuación? ¿Qué tienen estos cuerpos que los hacen singulares? ¿Qué sucede con una escena repleta de mujeres? ¿Cómo ensaya una mujer? ¿Cómo dirige una mujer? ¿Cuál es su operatoria que la diferencia de la masculina? ¿Existe una escena femenina en contraposición a la escena-macha ${ }^{2}$ que venimos arrastrando como único modo de hacer del teatro?

La puja entre una escena femenina y una masculina toma grandes dimensiones en nuestro proceso, primero porque la obra se crea en una coyuntura social de luchas feministas que nos permitieron observar la necesidad de detenernos a repensar prácticas individuales para poder desandar y deconstruir procesos colectivos profundamente machistas. Y segundo porque a partir de esos mismos procesos fue que comprendimos que como actrices nos debíamos la revisión de las prácticas específicas de nuestro hacer en el campo teatral. lo colocamos en el mismo lugar jerárquico que al proceso creativo, deseábamos encontrar formas diferentes de ser y habitar la creación escénica, y de ese modo revindicar nuestro rol y los espacios que merecemos dentro del hacer teatral que al menos en nuestra provincia es un territorio guiado y regido por varones.

\footnotetext{
Escena-macha término utilizado por Guillermo Cacace (director teatral argentino) en un seminario sobre actuación dictado en Mendoza (Argentina) en marzo de 2018
}

Si seguimos el planteo anterior podemos afirmar que la escena teatral ha sido históricamente, una escena-macha, y de allí advertir que específicamente el campo de la dramaturgia no es la salvedad. Los procesos de escrituras escénicas colaborativas, han ido deformando estas premisas ligadas a un autor-padre y a la hegemonía del texto escrito. Los estudios de Hans- Thies Lemman $^{3}$ muestran como una gran porción de obras teatrales y performances se vinculan al texto de un modo desjerarquizado y descentralizado. El texto en la actualidad se convierte en un material dotado de nuevas singularidades, su evidente corrimiento de un lugar de centralidad durante el siglo XX le permite hoy por hoy un juego de operaciones y procedimientos sobre sí mismo que para la teoría del drama del siglo XIX era impensada. Si ahondamos en la problemática en torno al eje texto también deberíamos encontrar la histórica relación entre: autor- texto- dirección- texto- actor, actualmente en tela de juicio.

El trabajo no pretende ahondar en disquisiciones sobre literatura y teatro, polémica superada ya a esta altura tanto por la teoría teratológica como por el campo de la praxis en sí misma. Sin embargo, cabe aclarar que para pensar ciertas categorías es necesario advertir que las practicas escénicas actuales tienen como rasgo característico la desdelimitación, la multiplicidad y la heterogeneidad, por lo que seguir sosteniendo categorías cerradas y estancas no pareciera ser una buena decisión para estudiar el teatro actual. Partiremos de un marco teórico que analiza a su objeto de estudio comprendiendo su hibridación y heterogeneidad. Aquí podemos mencionar la teoría de la filosofía del teatro instaurada por Jorge Dubatti junto a su equipo de investigación de la UBA. Partimos también del concepto de cosmos teatral expuesto por Hans-Thies Lehmann en su libro Teatro posdramático, cosmos que por su heterogeneidad que lo caracteriza permite la coexistencia de materiales disimiles. Además, no menos fundamental es la importancia que cobran en este trabajo en particular los estudios sobre la práctica teatral que realizan los teatristas. Seguimos las distinciones que presenta Dubatti: artista-investigador e investigador-artista, y a partir de ellas es que tomamos las reflexiones de Eugenio Barba, Mauricio Kartun, Ricardo Bartis, Cipriano Argüello Pitt, entre otros teatristas que han generado teoría teatral en combinación con su hacer propiamente dicho. Finalmente, para cerrar esta introducción y retomando el planteo político con el que comenzamos la escritura, es necesario aclarar que este trabajo tiene como objetivo secreto colocarse en un entremedio entre teoría y práctica teatral, porque adherimos al pensamiento de Argüello Pitt "la relación entre teoría y práctica son intrínsecas así mismas; de hecho, la actuación, la dirección, la dramaturgia y toda practica vinculada a la escena es un pensamiento en acto" (2013). Trabajos de investigación como los de Carla Pessolano y

\footnotetext{
${ }^{3}$ Hans-thies Lehmann ha ahondado sobre este tema en diferentes estudios, pero especialmente en el prólogo de su libro El teatro posdramático editado al castellano en el año 2013 por editorial Paso de Gato
} 
Denisse Cobello o bien el que viene generando Documenta Escénica en la provincia de Córdoba, han servido de ejemplo y como impulso para poder llevar a cabo un trabajo de este tipo. Solo por un instante la voz de quien escribe se individualiza porque entiendo que de algún modo esta decisión de reflexionar sobre un proceso en el que he participado desde la dirección escénica me abre la posibilidad de instalarme políticamente frente a la escena y también, por qué no, en los espacios de legitimación de los estudios teatrales. El escrito irá tejiendo de un extremo hacia el otro las relaciones necesarias para dar cuenta de un proceso que estuvo ligado desde un inicio a estos interrogantes teórico-prácticos. En esta instancia, dejar relegado el cuerpo que fue partícipe del proceso escénico es equivalente a afirmar que en la escena el cuerpo no piensa. Es el deseo profundo de este trabajo acortar las distancias entre dos polos que la academia y la práctica teatral se han empecinado erradamente en separar históricamente.

\section{NOCIÓN DE GRUPO}

En mayo de 2016 las directoras de Inventario convocan a actrices para trabajar en una producción escénica de investigación: sin texto a priori y sin fecha de estreno. Los primeros meses, además de investigar procedimientos de creación y materiales escénico-textuales, sirvieron para armar el grupo que finalmente daría forma a la creación. Desde el primer día de ensayo hasta el momento (ya iniciada la segunda temporada de funciones), no nos definimos como elenco ni como grupo con nombre que nos identifique. Esto no quiere decir que no tengamos identidad grupal, la obra se ha encargado de ofrecernos una dentro del campo y de algún u otro modo nos reconocen bajo ciertas referencias: "la obra feminista; la obra de género; las chicas de Inventario; la obra de mujeres". La pertenencia al espectáculo confecciona de por sí una identidad. Es sabido que la noción de grupo, al menos en Argentina junto con los procesos de posdictadura, se ha ido modificando a lo largo del tiempo, los grupos históricamente llamados independientes $^{4}$ han mutado hacia estructuras abiertas $\mathrm{y}$ flexibles que les permiten en la actualidad conformarse bajo las características de la asociación, las redes de trabajo, el trabajo colaborativo. De la noción tradicional de grupo independiente solo conservamos dos aspectos: lo temporal ya que el proceso de producción contó con más de un año y medio de investigación. Y por otro lado la constitución de una identidad propia. El resto de las características ubican al grupo dentro de los márgenes de los nuevos modos de producción teatral, sistemas más abiertos y eclécticos, los grupos en la actualidad responden a “(..) nuevos modos de hacer. Estos más complejos, menos claros, mas híbridos.” (Halac, 2006). Quienes hacen inventario, en su mayoría, trabajan en más de un

\footnotetext{
${ }^{4}$ Leónidas Barletta en 1930 crea el primer grupo de teatro independiente llamado Teatro del pueblo, grupo que fundó un modo de producción y un circuito teatral en sí mismo, con el tiempo proliferan grupos con la marca
}

espectáculo; todas realizan tareas por fuera del campo de la actuación y la dirección escénica (docencia teatral, docencia de otro tipo y trabajos remunerados a corto y largo plazo de diferentes rubros); la mayoría ha indagado en más de un rol dentro del teatro (actuación, dirección, técnica, etc) y en algunos casos en otras disciplinas artísticas (audiovisual, danza, música, etc).

Además de estas características puede resultar interesante para comprender la conformación de este colectivo la capacidad de gestión de las integrantes, este tipo de capacidad es analizada en un artículo sobre teatristas contemporáneos de Buenos Aires por los investigadores Rimoldi y Monchietti. En el artículo titulado Una cohorte de artistas porteños (2016) exponen la figura de un artista-gestor y observan que dentro de las grupalidades (que son eventuales en su mayoría) se conforman sistemas de asociaciones entre artistas. La imagen de red sirve para imaginar en particular los modos de producción en Mendoza, y en general, la mayoría de los centros artísticos de Argentina. Un dato que nos interesa destacar del estudio de los investigadores recién mencionados es que los artistas se vinculan unos con otros formando lazos de afinidad y amistad, y es esta resonancia afectiva lo que los convoca a trabajar unos con otros, entre ellos crean un eco sistema de creatividad (Rimoldi y Monchietti, 2016). En nuestro caso los lazos afectivos fue una ganancia con la que no contábamos desde un principio, el grupo debió construir estos lazos a partir del encuentro semanal en los primeros meses de iniciada la propuesta, por lo que el ensayo funcionó como incubadora de estas relaciones. El ensayo permitía crear un nuevo código y lenguaje que perteneciera únicamente a este colectivo en particular. La dinámica de trabajo fue apareciendo a la par del encuentro de materiales escénicos.

\subsection{El ensayo teatral}

El ensayo es un núcleo importante para la reflexión teórica del proceso de esta obra. Esa separación del tiempo y del espacio ordinario a un espacio-otro el del ensayo es lo que permite a los colectivos conformarse como tales, es decir, con una cierta identidad (aunque muchas veces sea dificultoso nombrarse). El ensayo en su constitución propone una separación témporoespacial, hay un adentro y un afuera claro y el tiempo en este espacio se desdobla: el mundo sigue su ritmo cotidiano afuera de la sala de ensayo, dentro de ella el tiempo se percibe diferente. El modo de estar dentro de este espacio dependerá de las condiciones de trabajo, el director o coordinador deberá realizar ciertas actividades para que el afuera no ingrese al espacio íntimo del proceso creativo.

El ensayo pareciera tener sus reglas, la misma experiencia dentro del campo -como dice Arrojo (2014) nadie te enseña a

de independiente, muchos de ellos surgen a partir del estatuto fundacional del grupo de Barletta. La noción de grupo en argentina viene de este inicio en la década del '30 en Buenos Aires. 
ensayar- permite conocer algunas de las reglas que podríamos asumir que se heredan, pero otras se crean bajo las decisiones del colectivo, la regla del ensayo está allí por una razón y su cumplimiento debería asegurar la efectividad de una producción escénica. El ensayo es por sobre todas las cosas un entramado de posicionamientos políticos y éticos frente al trabajo artístico, que pueden ir desde la puntualidad y la vestimenta para ensayar, hasta el modo en que abordamos un cuerpo, los modos en los que la dirección aborda al acrtor/actriz, la forma de relacionarse con los materiales de la escena, etc.

El manual invisible, heredado, sobre cómo ensayar nos dice que es necesario "acordar códigos que expresan los comportamientos deseados, coordinar desde allí la tensión entre las necesidades personales y las colectivas, darle batalla al afuera que complota contra el tiempo y el espacio de la creación ", (Arrojo, 2014). El actor debe estar allí presente para la escena separándose de su cotidiano, debería (mediante su ética de trabajo) desprenderse del afuera para dar lugar a la creación, si lo que se quiere es avanzar con la productividad y la efectividad del ensayo. Desde nuestra experiencia, recortada y singular, creemos que este mandato está construido sobre una idea falaz. Porque justamente, como dice Argüello Pitt, el cuerpo es irreductible a sí mismo. El cuerpo es lo único que la representación no puede enmascarar totalmente. Las actrices se presentaban a la jornada de trabajo cargando en su cuerpo una cantidad de sensaciones, afectaciones, memorias, necesidades, preocupaciones, temores, que no era posible dejar en la puerta de entrada para ser retiradas en la salida como quien busca su abrigo en un guardarropa. Porque son huellas que están inscriptas su modo de estar y de ser presencia, así quedaba demostrado de un modo muy explícito cómo en el teatro el cuerpo es el puente con lo real, justamente porque lo real se instala en el cuerpo.

Cuando pudimos reconocer que no queríamos obedecer este mandato-ensayo, la obra comenzó a dar un giro que nos transformó en absoluto. Comenzamos a trabajar con esas cargas transformando la charla inicial en cantero de materiales autobiográficos para ser comprendidos y transformados por la escena. Los materiales escénicos y textuales con los que veníamos trabajando comenzaron a tener una lógica interna en vinculación con los relatos propios que traíamos a los ensayos, el material así tomaba forma y se expandía.

Una vez encontrada esta pista, los materiales que seleccionábamos estaban en consonancia con esa línea interna, lo biográfico se reescribía con los materiales textuales y viceversa. No hubiera sido posible desestimar este camino, porque los cuerpos incluidos los de las directoras vibraban en esa misma frecuencia, estaban siendo atravesados por los mismos dolores, por los mismos miedos, por las mismas preguntas: ¿qué es ser mujer? ¿Y qué ser actriz? ¿Cómo puedo seguir siendo la misma con tanto dolor? Gracias al afuera teníamos razones para formar en el colectivo una identidad. La escucha nos dio el procedimiento y el contenido, aun cuando el contenido fue la forma.

\section{ESCRIBIR PARA CUESTIONAR, CUESTIONAR PARA ESCRIBIR. Prácticas colaborativas y dramaturgia ampliada}

Reescribir desde el cuerpo fue una premisa mucho anterior al descubrimiento del procedimiento biográfico, la escena ensayo tras ensayo iba generando la dramaturgia con la que trabajábamos, las operaciones sobre el cuerpo en el espacio generaban un estar y un modo de decir que afectaba toda posibilidad de texto preconcebido.

Como mencionábamos en la introducción, el texto teatral ha sido el foco de las discusiones durante los últimos siglos en el campo de la teoría teatral. El problema actualmente no pasa por: texto si o texto no, porque podemos corroborar en la actualidad que más allá de los deseos artaudianos de erradicar la literatura de la escena, hoy por hoy el elemento texto sigue formando parte de las prácticas teatrales, la producción dramatúrgica es vasta y no deja de editarse. Lo que estuvo y está en cuestionamientos es el modo en la que dicha dramaturgia se produce.

Josep Danan explica muy bien en su ensayo teórico ¿Qué es la dramaturgia? la diferencia entre una dramaturgia surgida de un autor tradicional, que se vincula solo desde la virtualidad y la imaginación con la escena, a la dramaturgia surgida desde la escena y en plena vinculación con la materialidad de la misma. El texto escénico, plantea Danan, elimina el tradicional arte en dos tiempos, y hace coincidir tiempo y espacio de escritura con el escénico. Esta variable espaciotemporal no debería implicar ponderar una sobre otra, lejos estamos de decir que el autor de escritorio no va más, sino convenir que esta segunda opción nos permite observar nuevas operatorias de escritura, ahora escénica, que implican directamente sobre el rol de la dirección y del actor, operatorias que han sido poco estudiadas por la teatrología y relegadas absolutamente por los estudios literarios. Al coincidir en el aquí y ahora de la escena el texto precisa ser estudiado junto con los vectores cuerpo y escena propiamente dicha.

Jorge Dubatti suministra una tipología para pensar las dramaturgias en relación a la escena: textos pre-escénicos, escénicos y pos-escénicos. A partir de ella podemos decir que nuestro trabajo es una escritura escénica a partir del juego con materiales textuales pre-escénicos de otros autores (teatrales y no teatrales) los cuales fueron reescritos, tergiversados, discutidos, trasgredidos, usurpados, explorados, explotados, intervenidos. Es clave quizás aclarar que ninguno de ellos fue utilizado de modo tradicional: texto a ser representado. 
Esto es una operación textual que no se presenta como novedad alguna, Danan en Entre teatro y performance. La cuestión del texto expone esta situación citando entre tantos otros a Joël Pommerat quien dice que actualmente no se deviene verdaderamente autor de teatro más que anudando de m anear estrecha el trabajo de escritura del texto con el trabajo de puesta en escena (2016). Y podemos decir aún más, no solo existe un cambio de paradigma en cuanto a la relación temporal de la escritura teatral, sino que además el texto adquiere otras dimensiones insospechadas por la teoría del drama anterior al siglo XX. El texto teatral actual cada día se parece menos a un texto teatral. Claro que debemos retomar la idea de cosmos teatral, este nuevo texto detonado y fragmentado, antidramático, convive con piezas que responden al concepto de pièce bien faite ${ }^{6}$. Contra la pieza bien hecha se propone un teatro rapsódico, en términos de Jean-Pierre Sarrazac. Lo rapsódico estaría en consonancia con el montaje y la yuxtaposición, de la fragmentación, de la hibridación entre lo narrativo y lo dramático, el archivo y documento, con una unidad que solo es posible como trabajo de lo heterogéneo, la continuidad como ruptura y la armonía como disonancia (2013).

En esta heterogeneidad es que el texto teatral aparece dentro de la obra como un elemento más del cosmos escénico y en muchos casos intervenido por el procedimiento del collage como si "no pudiera existir más que como material exógeno al teatro” (Danan, 2016). En nuestra creación el texto se constituía como un elemento más del mapa escénico, no era portador de signo, no contaba una historia, adrede fue eximido del histórico trabajo de construir sentido. Había momentos donde muchos textos se hacían presentes solo por gusto de ser oídos, como sonido no como melodía. El cuerpo de la actriz era melodía, el dispositivo escénico lo era, la palabra solo venía a ser parte de ese todo sonoro y visual, un entramado complejo donde todo es dramaturgia.

De algún modo, estábamos trayendo a escena la premisa barbiana: la dramaturgia como tejido ${ }^{7}$. Y con ello el encuentro de una dramaturgia ampliada. Para la cual, nuevamente Dubatti presenta vasto material para abordar las modificaciones de esta categoría, en varias de sus publicaciones expone la necesidad de contar con insumos teóricos que ayuden a profundizar esta ampliación del concepto dramaturgia, ampliación necesaria ya que los ejemplos son cada vez más vastos. Algunos de ellos se han constituido como obras teatrales claves de la cartografía del teatro argentino de posdictadura en Argentina, poéticas como la de Ricardo Bartis y el Periférico de objetos (los ejemplos son innumeralbes) encuentran consonancia con muchos procesos escénicos del resto del mundo (pensemos en la dramaturgia de

\footnotetext{
6 Pieza bien hecha, concepto tratado en profundidad por Jean-Pierre Sarrazac en Léxico del drama moderno y contemporáneo. Donde realiza con detenimiento un estudio sobre el concepto en relación a las prácticas contemporáneas teatrales que dan muerte al bello animal heredado de la teoría aristotélica, concepto instalado como paradigma organizador de la
}

dirección de T. Kantor, o Grotowski, en los trabajo de dramaturgia del actor y dramaturgia grupal del Odin Teatret, los procesos de prácticas colaborativas en Brasil, solo por nombrar algunos pocos). Los nuevos modos de escritura escénica precisan nuevas herramientas y metodologías de análisis que puedan dar cuenta de su profunda complejidad.

Para ahondar en el concepto de escritura escénica, entendemos que es necesario abordar el término escritura desde una desdelimitación del término, y fundamentar este borramiento del límite en lo que Jaques Derrida expuso en libro "De la Gramatología":

Se tiende ahora a decir "escritura" en lugar de todo esto y de otra cosa: se designa así no sólo los gestos físicos de la inscripción literal, pictográfica o ideográfica, sino también la totalidad de lo que la hace posible; además, y más allá de la faz significante, también la faz significada como tal; y a partir de esto, todo aquello que pueda dar lugar a una inscripción en general, sea o no literal e inclusive si lo que ella distribuye en el espacio es extraño al orden de la voz: cinematografía, coreografía, por cierto, pero también "escritura" pictórica, musical, escultórica, etc. (Derrida, 1986)

Pensar en lo que la hace posible nos habilita por un lado pensar en el cuerpo que la produce y por otro la dimensión procedimental de esa producción.

\subsection{Escribir en colaboración}

En una reciente publicación El cuerpo dramatúrgico (2017) compartíamos algunas premisas sobre la dramaturgia del actor en procesos similares al que hoy presentamos, allí es posible dar con rodeos teóricos en torno a la categoría dramaturgia escénica, en relación a la cual desarrollamos todo lo concerniente al cuerpo del actor como promotor de una dramaturgia singular. A ella deberíamos sumar en esta ocasión la dramaturgia de dirección escénica que en un trabajo de colaboración constante producen la dramaturgia final.

Inventario de un jardín que arde parte de tres tipos de escrituras: la de la dirección escénica, la de los cuerpos de las actrices y la de la materialidad escénica: espacio visual y sonoro. En la interrelación de estos tres realizadores de la escritura es que se da la intervención de procedimientos de dramaturgia por fuera de los modos tradicionales de escritura. Partimos de un trabajo de colaboración escénica a través de los

\footnotetext{
textualidad y de la escena, constituido como metáfora central de la estética occidental

${ }^{7}$ Este concepto se desarrolla de modo profundo en el libro escrito por Barba “Quemar la casa. Orígenes de un director". Para ahondar en estas nociones recomendamos su lectura, en especial del capítulo una "Una pluralidad de dramaturgias" (Barba, 2010. p. 33-40)
} 
diferentes dispositivos de creación. Para pensar el término colaboración es necesario traer a discusión las prácticas colaborativas en artes escénicas propuestas por varios autores, aquí recomendamos ampliar con las reflexiones de autores como Ary y Alpizar (2015) y Araújo (2010); y sumarle a ello algunas nociones básicas sobre escritura en colaboración procedente del campo literario, como lo es la escritura de dúos de autores.

Los trabajos colaborativos comprenden una dinámica creativa donde cada artista cumple un rol, dentro del procesos estos roles se verán afectados unos a otros, pasarán por diferentes instancias en las cuales la jerarquía del rol irá variando, es decir, no se trata aquí de una horizontalidad de roles ni ausencia de jerarquías, sino que cada rol tiene su momento de centralidad según la necesidad del proceso. A diferencia de lo que sucedía en las creaciones colectivas de los años '60 y '70 en las cuales la horizontalidad era un objetivo y utopía a ser alcanzada por la creación. En ambas metodologías creativas el rol del actor es fundamental. Aquí el cuerpo del actante deja de ser intérprete o cuerpo al servicio de otro orden (autor-texto-dirección) para tomar decisiones y convertirse en co-creador de la escena. Su cuerpo es en sí mismo fundador de sentido.

El producto final es un texto escénico a partir de un trabajo de collage, transtexualidad y reescritura de materiales teatrales y no teatrales. Antes de poder analizar estos procedimientos en particular es preciso detenerse en el cuerpo como componente fundante de la escritura escénica. Las operaciones que realizan las actrices en el espacio a partir o no de un material dado fundan la escena misma, podríamos afirmar aquí la idea bartisiana que dice que hasta que no hay potencia de cuerpo en el espacio no hay teatro ${ }^{8}$.

\subsection{Cuerpos}

"No aceptar el modelo idealista de la belleza y de la obra terminada. No someterse a las reglas del mercado y a las apetencias del público. Existe un elemento novísimo que es el cuerpo vivo del actor, que instala una presencia singular y trata de extender el tiempo como acontecimiento, no como realidad" (Bartis, 2003)

En este proceso en particular esto toma una potencia inusitada, ya que para nosotras trabajar con el cuerpo vivo y singular significó al menos tres cosas:

1- Que el cuerpo en escena era un cuerpo femenino, seis cuerpos para ser más exactas, y que entre ellas formaban un cuerpo-colectivo.

\footnotetext{
${ }^{8}$ Ricardo Bartís expone su pensamiento teatral en el libro Cancha con niebla (2008), a partir de entrevistas realizadas por Jorge Dubatti va reflexionando en torno a categorías como texto, texto escénico y cuerpo del actor.
}

2- Que aceptar ese acontecimiento del cuerpo significaba la reescritura del cuerpo sobre la escena. Y que la reescritura sería constante y no finaliza ni siquiera al terminar la etapa de ensayos.

3- Y, por último, y en vinculación total a lo anterior, que comprender la singularidad nos enfrentaba a aceptar al cuerpo como envoltura de una biografía en particular. Y que esto cobraba una potencia inusitada al cuestionar los materiales textuales desde la biografía personal de cada actriz

Si pensamos en los dispositivos o en los sistemas creadores de obra, podemos aquí afirmar que el cuerpo mismo de las actrices fueron fundadores de dispositivo. Cada actriz se situa a sí misma en la creación, por fuera de las marcas de personajes, por fuera de la construcción de un sentido otro, su cuerpo es su cuerpo, sin mediación representativa. Nos preguntábamos durante el proceso que particularidades tiene ser mujer y ser actriz, una pregunta latente y tácita, porque vino a ponerse en palabras cuando contábamos con más de la mitad del material. Para hablar del cuerpo podemos traer a la reflexión 58 indicios sobre el cuerpo de Jean-Luc Nancy, el filósofo dice: "el cuerpo es una envoltura: sirve, pues, para contener lo que luego hay que desenvolver. El desenvolvimiento es interminable. El cuerpo finito contiene lo infinito, que no es ni alma ni espirito, sino desenvolvimiento de cuerpo" (2017). El cuerpo así, por su trabajo de desenvoltura expone dos situaciones ante la creación escénica, que al menos en nuestro trabajo tomo grandes dimensiones: la diferencia del cuerpo con otros cuerpos, y su permeabilidad.

En relación a la diferencia, podemos decir que hubo una profundización de la misma desde una visión tematológica, como la diferencia del cuerpo femenino en relación a uno masculino. Detenernos en la diferencia, resonó en el grupo como urgencia y necesidad para ser tratada en la obra, una pregunta se acentuaba ¿se puede escindir lo político del cuerpo? teniendo en cuenta las marcas temporales en las que se inscriben nuestros ensayos, esta pregunta se potenciaba, y nos hacía tomar postura desde la creación misma. La realidad y el contexto socio-cultural en Argentina de los últimos años, procesos acelerados en los últimos meses, nos propiciaron un escenario perfecto para la toma de decisiones sobre el qué decir con la obra $^{9}$. Pero además debemos observar aquí, que también se trabajó dentro del género femenino la diferencia establecida entre las mismas actrices, y la búsqueda de una unidad posible únicamente en la aceptación de esas diferencias.

En relación a la permeabilidad del cuerpo y su constante fluctuación es que la obra posee muchos momentos donde lo real del cuerpo y su presente escénico, inscriben el espectáculo

\footnotetext{
${ }^{9}$ Argentina viene generando una ola feminista singular con mayor adhesión e intensidad en los últimos tres años: Marcha de Ni una menos; lucha por la legalización del aborto; lucha por políticas sociales para las víctimas por violencia de género; encuentros nacionales de mujeres, entre otros.
} 
como ruptura de la convención. El espectador que es provocado constantemente en torno a la pregunta qué es ficcional y qué es real, (las actrices se presentan con sus nombres reales y dicen exponer parte de su vida en escena), se transforma en testimonio vivo de diferentes relatos que al pronunciarse en nombre propio toman una dimensión real que arremete contra la ficción, rompe así con el pacto tácito de la convención teatral.

Para el proceso escénico la biografía particular de cada actriz no solo funcionó como materialidad escénica sino como sistema ordenador del resto de la materialidad. Fue mediante un proceso de selección a partir de las resonancias del cuerpo en escena con determinados materiales que se fue haciendo el acopio de diferentes textos. El dato biográfico no bastaba para construir obra, no era en sí mismo dramaturgia, debíamos hacer con ellos un proceso de rescritura escénica. Así lo biográfico en relación a otros materiales fueron generando el texto final con el que hoy contamos, podemos mencionar aquí algunas de las operaciones textuales que utilizamos: ejercicios de collage, la cita, preguntas al texto, rapto de estructuras, armado de listas personales, acopio de anécdotas propias y de otras mujeres, entre otras. Los materiales se unían unos a otros por resonancia en la misma escena, el tratamiento de alguno de ellos dependió siempre de cómo este era habitado en la escena.

\subsection{Desjerarquización y simultaneidad ${ }^{10}$}

El tratamiento del resto del material textual fue atravesado por dos condicionantes: la desjerarquización y la simultaneidad. Durante el proceso íbamos haciendo acopio de materiales textuales y no textuales, teatrales y no teatrales: fragmentos de obras clásicas y contemporáneas; pasajes poéticos y narrativos de escritores canónicos como Girondo, Pizarnik y Cortazar, en contraste y dialogo con poesía contemporánea como la de Victoria Aldunate, que se inscribe en una poética por fuera del canon; también entraron en juego los universos de los relatos infantiles como el de Blancanieves y el de Barba azul; noticias de diario local y nacional; estadísticas; mitos griegos; materiales visuales como cuadros de pintores renombrados; las letras de las canciones de Lola Arias y los universos musicales de Ulises Conti. Además, claro está, de las biografías recién mencionadas.

Todo esto formó parte del entramado de reescritura dramatúrgica que se realizó, los materiales fueron manipulados sin orden jerárquico, es decir, todos los textos canónicos o no, teatrales o no, tenían el mismo peso al comenzar el trabajo escénico. La decisión de primacía de un texto sobre otro era tomada únicamente por la escena misma. No había una idea ordenadora a priori de los materiales, los mismos se trabajaban en simultáneo y completamente atravesados por la materialidad escénica. El orden fue posterior.

\footnotetext{
${ }^{10}$ Ambas nociones en lo que respecta a la desjerarquización del texto en relación al resto de los signos teatrales y la simultaneidad como concepto
}

La reescritura y el collage son procedimientos rupturistas por naturaleza, es necesario faltarle el respeto al texto, para reescribir el texto. Así el material debe ser dispuesto a operaciones como maximización, minimización, combinación, tergiversación, fragmentación, etc. Con la mayoría de los materiales nos sucedía que no nos servía el texto entero, del mismo solo quedaba una frase, una palabra que usábamos con reiteración, el efecto del texto pero dicho con otras palabras, una estructura de ordenamiento, una imagen y hasta una pregunta. El caso de la obra Crave es un ejemplo aparte, la poética de Sarah Kane fue una colaboradora fiel de la obra. Más que las obras en si era la autora la que debía formar parte del texto y creemos haberlo hecho posible, ya que aparece de modo literal, su texto es el único que aparece en la obra como si fuera una cita. Para nosotras fue un hallazgo dramatúrgico usar un fragmento de su obra teatral dentro de la nuestra como una cita literaria.

La dramaturgia final es un resultado de operatorias complejas de inadmisible separación entre dramaturgia de dirección y de actriz, el cuerpo escribía a partir de operaciones de la dirección escénica, y viceversa. Escritura de múltiples cuerpos y miradas, en la cual se trabaja sin jerarquización de roles y de modo simultaneo. Ahora bien, la desjerarquización no involucra, de todos modos, la anulación del rol de la dirección, cada rol existe con sus particularidades y sus tomas de decisiones, su campo de operaciones, la diferencia con otros modelos se instala en que el poder del director no está ligada al ordenamiento verticalista del sentido sino que el mismo es parte de un entramado complejo de decisiones durante todo el proceso, donde cada rol dentro de su campo y su especificación accionará hacia un resultado especifico. El poder así no se instala como en una imagen piramidal, donde el director o el autor están en la cima y desde allí bajan coordenadas, la imagen se transforma en una red de trabajo, donde cada núcleo de saber (actuación, dirección, escenotecnia, etc.) operan en relación a un mismo fin: la escena.

\section{ALGUNAS CONCLUSIONES}

El proceso creativo que dio lugar a la obra Inventario de un jardín que arde propició un juego rico y profundo de relaciones y acercamientos de dos núcleos que, históricamente, el teatro ha pretendido alejar: la práctica y la teoría teatral. Este artículo tenía como pretensión acercar estos dos extremos y permitir poner en cuestionamientos algunas nociones que, una vez más históricamente, encasillan con definiciones cerradas y estáticas al texto dramático, al cuerpo del actor y a las respectivas relaciones tendientes entre ellos. A lo que habría que sumar los modos tradicionales de producción escénica.

La obra que escogimos para analizar propone nuevas disposiciones creativas, por lo tanto, reclama nuevos modos de

fundamental de las prácticas escénicas contemporáneas pueden ampliarse en Teatro posdramático de Hans-Thies Lehmann 
análisis y metodologías para la investigación. Desde un marco teórico ecléctico que comprende la filosofía, la teatrología y algunas relaciones con la sociología, es que pudimos observar los nuevos modos de prácticas teatrales contemporáneas y las preguntas que las mismas plantean en la actualidad.

Las dramaturgias contemporáneas abren la posibilidad de ampliación del campo teatral por las nuevas vinculaciones con materiales extra-teatrales, pero sobre todo por el encuentro de procedimientos de escritura escénica que permiten escindir los límites entre lo puramente ficcional y real; entre lo teatral y lo extra-teatral; entre la palabra y la materialidad. Se crean así, objetos artísticos que buscan relacionarse con el azar, lo real, el acontecimiento y la performance.

Las nuevas dramaturgias nacen a partir de procesos de permeabilidad y se pueden observar cambios en los modos de hacer teatro, ahora más híbridos y más flexibles. Así es que vimos como la noción de grupo se ha podido transformar para estar acorde con los nuevos modos de hacer, lo que dispone ahora nuevos modos de ser y estar en el ensayo teatral, diferentes formas de pensarse en escena y fuera de ella. Inventario de un jardín que arde es solo un ejemplo entre muchos otros que se dan en la actualidad de la cartografía teatral de Argentina, sin embargo, el ejemplo sirve como afirmación de dos ideas fundamentalmente políticas: por un lado, la deslimitación de la categoría dramaturgia y su evidente ampliación, y por otro la indispensable necesidad de reflexionar sobre el teatro desde las mismas prácticas teatrales, acortando cada vez más las distancias entre pensar y hacer. Para que en el futuro sean más los trabajos que reflejen esa intrínseca e inseparable relación entre un cuerpo que piensa y un pensamiento que hace.

\section{REFERENCIAS}

-Argüello Pitt, C. (2006), Nuevas tendencias escénicas. Teatralidad y cuerpo en el teatro de Paco Giménez. Córdoba: Ediciones DocumentA/Escénica

(2015), Dramaturgia de la dirección escénica. México: Toma, Ediciones y producciones escénicas y cinematográficas: Paso de Gato

(abril/julio de 2009). El nosotros infinito. Creación colectiva y dramaturgia de grupo. Revista Picadero, volumen (23) pp. $3-5$.

Araújo, A. (2010) Dramaturgia en el colectivo: intervenciones en espacios urbanos y "proceso colaborativo" en Teatro Da Vertigem. En: Repensar la dramaturgia. Murcia: Centro Párraga

Arrojo, V. (2014) ¿El director es o se hace? Procedimientos para la puesta en escena. Buenos Aires: Inteatro

Ary, R. y Alpizar, Y. (marzo de 2015). Proceso colaborativo en artes escénicas: Brasil y Costa Rica. Telón de fondo, volumen (21) pp. 61-66.

Barba, E. (2010), Quemar la casa. Orígenes de un director. Bueno Aires: Catálogos

Bartís, R. (2003), Cancha con niebla. Teatro perdido: Fragmentos. Buenos Aires: Atuel
Danan, J. (2012), Qué es la dramaturgia y otros ensayos. México: Toma, Ediciones y producciones escénicas y cinematográficas: Paso de gato

(2016) Entre teatro y performance: la cuestión del texto. Buenos Aires: Artes del sur

Dubatti, J. (2002), El teatro jeroglífico. Herramientas de poética teatral. Buenos Aires: Atuel

(2008), Escritura teatral y escena. El nuevo concepto de texto dramático -Montevideo: MEC.

Fischer-Lichte, E. (2014), Estética de lo performativo. Segunda edición Barcelona: Abada Editores

García Wehbi, E. (2012) Botella en un mensaje. Obra reunida. Córdoba: Alción editora y Ediciones Documenta/Escénicas

Halac, G. (2006) Teatro independiente en Córdoba. Identidad y memoria. Cuadernos de picadero, volumen (11)

Irazabal, F. (abril/julio de 2009) De la reacción a la técnica. Revista Picadero, volumen (23) pp. 6-7.

Kartun, M. (2015) Escritos 1975-2015. Buenos Aires: Colihue

Lafon, M. y Benoit, P. (2008) Escribir en colaboración. Rosario, Beatriz Viterbo

Lehmann, H. (2013) Teatro posdramático. ed. Castellana. México: Toma, Ediciones y producciones escénicas y cinematográficas: Paso de Gato

Mansur, N. (2014), "Dramaturgia del actor, dos casos de estudio: María José Gabin y Pompeyo Audivert". Revista de artes escénicas Quito-ecuador, El apuntador: http://www.elapuntador.net/revista/el-apuntadornro58/deotrastablas/dramaturgia-del-acto-nara-mansur/ última consulta febrero de 2017

Nancy J-L. (2017) Trad. Daniel Alvaro. 58 indicios sobre el cuerpo. Extensión del alma. Buenos aires: Ediciones La Cebra.

Sánchez, J. A. (1992), Dramaturgias de la imagen. La Mancha: Universidad de Castilla.

(2012), Prácticas de lo real en la escena contemporánea. México: Toma, Ediciones y producciones escénicas y cinematográficas: Paso de gato

Rimoldi, L. y Monchietti, A. (marzo de 2016). Una cohorte de artistas gestores. Taller de letras, volumen (59) pp. 111-123

Sarrazac, J-P (dir). (2013) Trad. Víctor Viviescas. Léxico del drama moderno y contemporáneo. México: Toma, Ediciones y producciones escénicas y cinematográficas: Paso de gato

Sloterdijk, P. (2011) Esferas. Madrid, Siruela 